\title{
The International Dimension of the Brazilian Higher Education System Through the Prism of South-South Cooperation
}

\author{
José Antonio Brum and Marcelo Knobel
}

\begin{abstract}
International cooperation is a growing trend among research universities. In the past, this took the form of collaboration between researchers in developing countries with those in the developed world that enjoy superior access to financial and technical resources as well as infrastructure. More recently, the collaboration map has begun to change, as scientists in developed countries recognised how local context can affect their work, and those in developing countries are slowly building their research capabilities. Furthermore, South-South research collaboration is considered increasingly important, alongside developments in science and higher education in these countries. Following a brief overview of the Brazilian higher education system, this article discusses the complexity of establishing international collaboration, citing a few programmes aiming at strengthening South-South cooperation.
\end{abstract}

Key Words: Higher Education, Research collaborations, South-South

La coopération internationale ne cesse de croitre au sein des universités de recherche. Dans le passé, elle prenait la forme d'une collaboration entre les chercheurs de pays en voie de développement et ceux de pays développés, qui ont accès à des ressources financières et techniques ainsi que des infrastructures supérieures. Plus récemment, le format des collaborations a commencé à changer, alors que les scientifiques des pays développés reconnaissent la manière dont le contexte local impacte leur travail, tandis

ABOUt the AUthors: josé AnTONio BRUM is a full professor at Instituto de Física Gleb Wataghin (IFGW), University of Campinas (Unicamp), Brazil. E-mail: brum@ifi. unicamp.br MARCELO KNOBEL is Rector and full professor at Instituto de Física Gleb Wataghin (IFGW), University of Campinas (Unicamp), Brazil. E-mail: knobel@ifi.unicamp.br 
que ceux des pays en voie de développement créent doucement des capacités de recherche. Par ailleurs, la collaboration de recherche sud-sud est de plus en plus considérée essentielle, parallèlement aux développements de la science et de l'enseignement supérieur dans ces pays. Après une brève introduction au système d'enseignement supérieur brésilien, cet article aborde la complexité de la mise en place de partenariats internationaux, en faisant référence à quelques programmes visant à renforcer les coopérations sud-sud.

\section{Introduction}

Science has increasingly become a more collective effort. A conducive environment that promotes intensive exchange of ideas and information, and incentives to improve our knowledge, are important conditions in developing a research project. Knowledge development and technological progress have transformed scientific research into an increasingly sophisticated endeavour that requires well-established laboratories with high-tech equipment and advanced technical support. These conditions drive scientific cooperation between researchers in developing countries and well-established research groups in the US and Europe. They also tend to undermine South-South collaboration because partnerships with developing or less developed countries do not offer the same opportunities to upgrade the local scientific environment. However, this situation has begun to change in recent years. There are three main reasons. The first is that SouthSouth dialogue promotes more equal collaboration, which is frequently more rewarding. Second, and perhaps most important, many of the problems confronting less developed societies are not a priority for developed countries' research agendas. Examples include neglected diseases and softmatter electronics, among others. Tackling these issues requires scientific and technological development, opening the door to South-South collaboration. Indeed, most of the collaboration programmes spearheaded by the authorities in such countries focus on such themes. A third and increasingly important reason is that more intensive South-South collaboration is associated with advances in communication technologies. The Internet, Skype and the automation of sophisticated experiments enable effective long distance collaboration without the need for displacement. Fruitful and frequent discussions can take place with researchers in different parts of the world. Seminars, courses and conferences can now be attended and participated in without being physically present. Many experiments can be operated remotely. This is changing the nature of international collaboration and creating new patterns in South-South collaboration. Given these conditions a new phenomenon of South-South-North collaboration is emerging, with scientists in the laboratories of developed countries 
increasingly focused on the priorities of the southern hemisphere. Recent interest in the problems in developed countries is also a consequence of globalisation and increasing human displacement.

Today, most universities and research institutes are looking to enhance internationalisation, not only through faculty and student exchange programmes, but also by means of international agreements with partner universities (Altbach, and Salmi, 20II). Indeed, most quality assessments, including the debatable international university ranking system, consider international commitment as a very important proxy of quality. Most of these rankings evaluate research universities taking into account the degree of internationalisation, measured by the number of international faculty members and students as well as international reputation, among other variables. One of the main considerations is the number and impact of published papers, and another is the international visibility of the publication (i.e., it should be published in journals with international circulation, usually in English).

Collaboration is increasingly pursued in order to increase productivity and the impact of the research. From the perspective of developing countries, it is clear that they would benefit from South-South cooperation, considering that they share many common challenges and have a mutual understanding of the cultural, bureaucratic and political barriers confronting them. It is thus worth examining the most effective ways to promote the scientific development of emerging regions by means of international collaboration. Stable partnerships are often established as a result of meeting foreign colleagues in workshops, conferences and symposia. Cultural affinity, access to resources for cooperative study and comparable levels of academic excellence and technological development all promote collaboration (Jeong, Choi, and Kim, 20II). While the Internet has enhanced long-distance communication among scientists, evidence shows that most collaboration begins with personal contact (Jeong, Choi, and Kim, 20II).

Although cooperation can be beneficial, not all partnerships work effortlessly and effectively (Knobel et al., 2013). Misunderstandings, different jargon, unrealistic expectations, mismatched capabilities, political instability and excessive bureaucracy undermine effective cooperation. This can result in frustration, wasted resources and misused opportunities. A report by the Global Science Forum of the Organization for Economic Cooperation and Development (OECD) provides an overview of good practices and suggestions to improve international collaboration (Organization for Economic Co-operation and Development, 20II). It stresses the contribution of collaborative work in building the research competence of each partner, which is considered the most important long-term impact 
of cooperative programmes sponsored by funding agencies. The report emphasises the need for "an optimal balance between the imperatives of research (bottom-up initiatives, peer review, etc.) with top-down strategic development priorities" (Organization for Economic Co-operation and Development, 20II). It also notes that any potential collaboration should pay attention from the outset, not only to the way its results will be assessed - whether in scientific or in social terms - but also how they will be communicated to both policymakers and the public. Some of the ideas presented are less apparent but just as important. For example, the report highlights the importance of a supportive policy atmosphere for research collaboration, emphasising the role governments can play in cutting through red tape and minimising bureaucracy. In also warns of the dangers of relying on political support, particularly in unstable situations where sponsorship can disappear overnight with a change in government (Dickson, 20II).

Brazil offers many interesting perspectives in the South-South collaboration scenario. The country is a strong emerging economy and an important player in the contemporary world. Brazil's Gross Domestic Product (GDP) reached US\$2.3 trillion in 20I4, around 3.8 percent of the global economy. It is also the largest country in its region, with a population of more than 200 million. Having achieved universal coverage in primary education, Brazil is now seeking to improve the quality and outcomes of its education system, especially at basic and secondary levels. The post-secondary education scenario is also changing rapidly, balancing the interplay between history and tradition; economic development; regulation and accreditation. Higher education (HE) plays a fundamental role in finding solutions to the significant challenges confronting Brazil in sustaining economic growth while achieving social justice. Investment in education and infrastructure are the two primary requirements to achieve a steady GDP growth rate above the historical average of 2 percent that is necessary to promote a more socially balanced society and enhance the country's international status.

\section{Overview of the Brazilian Higher Education System}

Brazil adopted different processes to promote universal access at the different levels of education. One can separate elementary and secondary education at one extreme and HE or post-secondary education at the other. A brief overview of the elementary and secondary education system is required to understand the current state of HE.

In the I970s, Brazil adopted policies to achieve universal elementary and secondary education up to the age of $\mathrm{I} 8$. That called for significant enlargement of the secondary school population. As part of these edu- 
cational reforms, secondary schools that were previously divided into technical schools that prepared students for professional positions, and those that offered a scientific education to prepare for university were merged. This resulted in an increasing number of students seeking access to universities. During the I980s, Brazil suffered an economic crisis with hyperinflation for more than a decade. While universal access was achieved at primary and secondary public schools, educators' salaries were severely affected by this economic meltdown. On the other hand, public universities managed to maintain reasonably attractive remuneration packages and research activities became an important part of faculty's activities. However, the price was a limited number of public universities. Increasing demand for HE was met by the private sector that accommodates 75 percent of students in the country. However, they generally offer lower quality education and less competitive working conditions. The net consequence was migration of children from the upper and high-middle classes to expensive private elementary and secondary schools. There is intense competition for places in public universities and most are gained by students that attended private secondary schools. The consequences include: a) social imbalance with education being one of the mechanisms for wealth concentration, b) reduced competitiveness among students with most being ill prepared for HE.

Brazil has an unusual post-secondary education system, with a relatively small number of public (federal, state, or municipal) research universities (tuition free), and a large number of private institutions, both philanthropic/faith-based and profit-oriented. Almost two-thirds of the private institutions are for-profit and many are of questionable quality. There is also a small but growing segment of vocational post-high school education (about Io percent of total enrollment) and a fairly large distance education sector (around I.I million students). In 2013, more than 7.3 million students were enrolled in undergraduate programmes -73 percent in private institutions and 27 percent in public higher education institutions (HEIs) and 32,049 different undergraduate programmes were offered by 2,316 HEIs (3OI public and 2,OI5 private). ${ }^{\mathrm{I}}$

The enrollment capacity of public institutions is limited by their high per-student cost and dependence on federal or state funds. Generally, only around ro percent of applicants are accepted. Success is linked to family circumstances (mainly parents with tertiary education) and high quality secondary education (frequently private). Thus, students from wealthier families have an advantage over those from poor backgrounds, who end up

1. Most of the statistics are from the Higher Education Census, promoted by INEP/Ministry of Education. See 'Censo da educação superior', at http://portal.inep.gov.br/web/censo-da-educacao-superior/resumostecnicos (accessed: 26 April 2016, in Portuguese). 
at private institutions with less rigorous selection criteria and lower quality education.

Higher education institutions are organised according to the European tradition. Many research universities have an extremely competitive selection process (the so-called vestibular) as well as a numerus clausus. To give an idea of how competitive the system is, the 2016 'vestibular' at the University of Campinas (Unicamp), one of the more important public research universities, had approximately 78,000 applicants for just over 3,300 places, representing only 4.3 percent.

The HE system has witnessed unprecedented growth, with enrollments doubling in the past ten years. From 2012 to 2013 enrollment increased by 3.8 percent, with around 2.7 million freshmen. The number of graduates is around a million per year, indicating a rather high dropout rate. Although the numbers could seem impressive, only around I8 percent of I8 to 24 year olds are currently enrolled in an undergraduate programme. If the pace continues at the 2012 rate, the cohort enrollment would only reach 34percent (OECD average) in 2022.

Furthermore, there is an inherent flaw in the existing arrangements. Tuition-free public institutions tend to enroll students with better qualifications from wealthier families. The majority of the private institutions focus on low-income students and offer night classes as most of those enrolled work during the day. While 70 percent of students at public institutions are enrolled in day programmes, in private HEIs 73 percent of students are in night programmes (usually from Ighoo to 23hoo). Private institutions cannot afford to hire full time professors or offer them packages that encourage scientific research, and rarely offer courses that require expensive laboratories or small classes. An integrated and diversified HE system is thus not within sight as institutions play different roles (technical education, research focused, teaching focused, etc.); and fall within different administrative categories (municipal, state and federal; private) and different academic organisations (universities, colleges, and university centres). They are disconnected and there are no opportunities for mobility among them or a plan for continuing education, in which people could come and go according to their personal and professional needs.

However, important recent trends are slowly changing the face of $\mathrm{HE}$ in Brazil. Technical/vocational three-year programmes (both public and private) are now on offer focusing on training in areas and subjects not included by traditional academic HEIs. Public programmes of this kind have witnessed significant growth in past few years. For example, enrollment in the Federal Institutes of Education, Science and Technology (IFETs) increased from about 31,000 to IOI,600 between 2006 and 201 I. The public technical colleges of the State of São Paulo (known as FATECs) 
saw enrollment grow from 10,000 in 200 I to 20,000 in 2011 .

There has also been a substantial growth in undergraduate distance programmes in the past few years. Enrollment increased from 5,000 in $200 \mathrm{I}$ to $\mathrm{I}, \mathrm{I} 53,572$ in $20 \mathrm{I} 3$, accounting for $\mathrm{I} 5.8$ percent of undergraduate enrollment. This is a recent trend, which is far from reaching saturation. Although federal and state governments have proposed some public initiatives (Universidade Aberta do Brasil, Univesp), most enrollments in distance education are in the private sector (83.7 percent in 2012).

Brazil has separate systems for quality assessment at undergraduate and graduate levels. The National System of Higher Education Evaluation (SINAES) assesses undergraduate education; it incorporates a test to evaluate learning outcomes known as the National Exam of Student Performance (ENADE). Graduate programmes are evaluated by the national Graduate Education Agency (CAPES).

From its inception, SINAES has based its evaluation on three axes - institutional, programme and undergraduate student proficiency. The ENADE exam taken by graduating students assesses proficiency in topics determined by the National Curricular Authority for Undergraduate Programs. Institution and programme evaluation is based on data collected by the Ministry of Education and on self-evaluations conducted by institutions. A full assessment cycle is completed every three years. The SINAES/ENADE process is under continuous review and sustains fruitful, ongoing public debate. The assessment system favours uniformity and just one model of a university committed to both teaching and research. Despite its limitations and issues of validity, the system aggregates data from institutions, grouped according to various criteria, and provides very useful information.

CAPES is responsible for the evaluation of more than 3,600 Masters and PhD programmes. Of the 200,000 graduate students in 2012, 93.4 percent studied in public universities. More than I2,000 PhDs and 4I,000 Master Degree certificates were awarded in 2010 . The graduate system encourages high quality research in both quantitative and qualitative terms. The expansion of research is evident in the number of published articles in ISI Web of Science indexed journals, which increased by I 8 percent in the past few years. In 2009, Brazil was ranked I3th in terms of the number of articles in this database $(32,100$ articles), which represents 2.7 percent of the articles produced worldwide. However, the average impact factor of Brazilian publications is below the world average, with rare exceptions in specific areas. These figures could improve, considering that only I.2\% of Brazil's GDP is currently spent on Science and Technology, a low percentage compared to other developed or developing countries. The country has recorded some success in the fields of Science and Technology, mainly in biofuels, agriculture and aviation, which is a direct consequence of sustained investment 
in public research universities, graduate education and research institutes. However, it is important to highlight that public spending on Science and Technology in Brazil is close to that of developed countries, percentage wise. The main factor that is lacking is the private sector's participation in such research. In general, efforts by the public and private sectors are close to equal, while R\&D is basically sustained by public investment.

\section{Research Universities and Research Networks}

Many current initiatives in Brazil aim to strengthen international research collaboration and student and/or faculty mobility. These include those spearheaded by individual universities with specific strategic plans, and bilateral or multi-lateral agreements among different universities and/ or funding agencies, with calls for proposals from international entities related to universities or science and development (for example, Academy of Sciences for the Developing World (TWAS); International Association of Universities (IAU), among others). There are also several international networks for common research proposals and mobility with specific goals or profiles. Their members mainly comprise research universities of regional or international importance. These include the Worldwide Universities Network (international), Asociación de Universidades Grupo Montevideo (regional in South America), Coimbra Group (Latin America and Europe), Grupo Tordesillas (Brazil-Portugal-Spain), and Grupo Magallanes (Iberoamerica), among others. These groups are very important because they bring together universities with similar profiles and aims, stimulating debate and exchange of ideas through meetings, workshops, and specific calls for mobility. Each research university specifies its priorities in collaborations and, from the perspective of long-term cooperation, bilateral projects with partner groups and/or universities are usually the best practice. Given the internationalisation imperative, following visits, hundreds of memoranda of understanding are now signed by universities and research institutes, without visible results in terms of improved research or student exchange.

It is thus preferable for a university to select a few international partners and build a long-term relationship. It is indeed hard to find sound and trustworthy partners, and it takes time and effort to sustain collaboration. Furthermore, effective collaboration is rooted in research teams working together, which often takes years to develop, because it essentially depends on human relationships, with common research goals. NorthSouth collaborations, with their various merits and challenges, feature highly in the published literature (Egwang, 2008). Unfortunately, there are still only a few multi-country collaborations where countries in the South work together, mainly in relation to health systems (Osama, 2008). This is despite the fact that many practitioners in less developed countries would 
be uniquely placed to assist scale-up efforts in other low-income countries with similar cultures and challenges (Ivers et al., 2010).

Brazil has witnessed a boom in international research opportunities. Its agencies such as CAPES and CNPq have for long issued annual calls for proposals for bilateral projects with different countries. There are also regular programmes for research collaboration, and specific calls for particular research fields. Besides public support, private groups and NGOs promote collaboration. Examples include Santander Bank's mobility programme ${ }^{2}$, Fundação Lemann ${ }^{3}$ and Fundação Estudar's study abroad programme ${ }^{4}$. In the past few years student mobility has drastically increased in Brazil, with the launch of the Science without Borders programme. The programme has resulted in more foreign universities recruiting students from Brazil's HE system. Although it has been criticised for various reasons (Knobel, 20I2), it was expected to increase the degree of internationalisation of Brazilian universities, with positive consequences for research collaboration. However, due to the country's economic crisis, the programme was put on hold in 2015 (Knobel, 20I5).

FAPESP is an interesting example of good practice in supporting mobility and international collaboration. Some of its programmes support research stays abroad or bring foreign researchers to Brazil. The agency also supports research meetings and workshops in the State of São Paulo. Since 2006 , it has concluded more than 60 collaboration agreements with foreign funding agencies and research institutions that generated more than 300 joint research projects which include exchange activities as well as joint research programmes 5 .

In the past few years, a set of programmes has expanded support for international collaboration. Commencing in 20II all of the I2,000 fellowship holders at FAPESP can choose to spend from four months to a year in a research laboratory or institution abroad doing work related to their project in Brazil (this programme is called the Grant for Research Studies Abroad - BEPE). Students enrolled in undergraduate, graduate and postdoctoral programmes are eligible for these grants. Proposals must show that the internship period will contribute significantly to the research project granted in Brazil. Another programme offered by FAPESP is short courses in advanced research in any area of knowledge in the State of São Paulo. The São Paulo Schools of Advanced Sciences (SPSAS) offer oneto two-week courses in advanced themes in science and technology. The

\footnotetext{
2. See https://www.santanderuniversidades.com.br/institucional/Paginas/santander-universidades-emnumeros.aspx

3. http://www.fundacaolemann.org.br/lemann-foundation/

4. See https://www.estudar.org.br/

5. http://www.fapesp.br/en/5399
} 
aim is to establish a globally competitive hub for talented young people in the State of São Paulo. SPSAS lecturers are scientists with excellent qualifications and prominence in their research fields, including foreign invited scientists. Students must be enrolled in undergraduate or graduate programmes and 50 percent must come from abroad and be potential candidates for masters, doctoral or post-doctoral programmes in HE and research institutes in the State of Sao Paulo. The latest programme supported by FAPESP is the São Paulo Excellence Chairs (SPEC) for top-notch foreign scientists with permanent positions abroad who are willing to spend at least I2 weeks for more than three years leading a research project in a university or research institution in São Paulo. The salary for the I2 weeks is paid by the host institution in São Paulo and research costs are provided by FAPESP. These scientists do not have to leave their jobs and can obtain additional funds for other projects in Brazil.

\section{IBSA and Other South-South Programmes}

Brazil participates in several bilateral and multilateral agreements for the development of science and technology, several of which are aimed at promoting South-South dialogue. Two examples are bilateral BrazilIndia cooperation in nanotechnology and the trilateral agreement under the IBSA (acronym for India-Brazil-South Africa) umbrella. The bilateral agreement in Science and Technology was established in 2003, and the first meeting took place in 2005 . The agreement was coordinated by the respective Academy of Sciences of Brazil and India. The priority areas are Biotechnology, Ocean Science, Materials Technology, Metrology and Information Technology. The IBSA agreement was a response to the collapse of the World Trade Organization's Cancun Conference. It seeks a new approach to South-South cooperation. Science and technology were among its first objectives. After the first meeting of the Ministries of Science and Technology from the three countries in 2004, it established cooperation in four main areas: health (focused on tuberculosis, malaria and HIV/AIDS), nanotechnology, biotechnology, and oceanography and Antarctic research. The initial steps were setting up scientific missions to make first contact and identify synergies among the three countries. The goal was a scientific and technological programme in areas that drew on expertise already developed in the countries as well as common priorities detected in the several missions from 2006 to 2008 . However, this initiative confronted several obstacles. For example, the nanotechnology project had a scientific and technological focus but also sought to involve students and young scientists through an exchange programme. The project was discussed and approved at a meeting of the three Ministries of Science and Technology in New Delhi in 2008, alongside other priority areas. Despite the strong 
emphasis on strategically oriented projects, the IBSA Science and Technology Agreement followed a more common path of funding trilateral calls for projects, disregarding initial efforts to establish clear goals and strategies to achieve these objectives. It is likely that one of the main difficulties was each country's strong attachment to their internal procedures and the lack of flexibility to develop instruments to fund the research project and promote scientists and students' mobility across the three countries. This hampered the efficiency and execution of the project. This is a common feature in emerging countries. Due to preoccupation with the proper application of the funding, they tend to establish strong regulations, leaving little space for initiative on the part of the scientific community. A severe difficulty faced by the scientists involved in the project was the different levels of commitment among the three countries. That led to a different funding agenda in each country, a consequence of local economic restrictions and level of commitment to the programme. This severely compromised the requirement of matching funds. Nevertheless, the initiative enabled some scientific exchange and joint projects on a less ambitious scale.

A scientific initiative among the BRICS (Brazil, Russia, India, China and South-Africa) countries was announced recently. It is still too soon to determine if the difficulties that confronted the IBSA agreements will be overcome in these programmes. However, it lacks coordination of the several multilateral agreements in science and technology. Furthermore, due to the lack of a central organisation, some redundancy and lack of effectiveness can be expected, particularly considering poor funding commitment and the low priority accorded to such programmes in all the participating countries. These factors hamper more fruitful South-South collaboration that is so necessary in the international research agenda.

\section{Conclusions}

Brazil's HE system recognises the importance of internationalisation and, in general, is addressing this issue. However, for this process to be efficient it has to confront several issues. The country's HE system developed more as a consequence of historical constraints rather than following a clear goal and strategic procedures. Consequently, a handful of research oriented public universities are responsible for education of the elite while basic higher education for the majority is provided by private institutions. Internationalisation efforts are mainly directed at research oriented HEIs, increasing the social and educational gap.

Internationalisation of $\mathrm{HE}$ and research are mandatory in an increasingly globalised world. However, for Brazil to develop an efficient HE internationalisation strategy, it first has to understand and organise its HE system following clear goals. These should promote the social, human and 
technological development of society. Furthermore, internationalisation should be part of an integrated strategy and should embrace the entire HE system. As it now stands, it is at risk of diffusing its effects, or, at best, perpetuating an already unbalanced HE system.

Notwithstanding these considerations, it is important to emphasise that South-South international cooperation agreements are important tools to promote the exchange of students and scientists as well as to develop focused research projects of common interest. However, these programmes require a complete overhaul. Commitment to such programmes, consistent funding, a coherent approach among the different programmes for improved effectiveness and an effort to simplify local regulations in favour of more cooperative efforts are necessary to render such agreements efficient tools for South-South international cooperation that mutually benefits regions in terms of sustainable development.

\section{References}

Altbach, Philip G., and Jamil Salmi, eds. (20II). The Road to Academic Excellence - The Making of World-Class Research Universities. Washington, D.C.: The World Bank. DOI: I0.1596/978-0-8213-8805-I.

Dickson, David. How to get the best out of research collaboration. SciDev. http://www.scidev.net/en/editorials/how-to-get-the-best-out-ofresearch-collaboration.html.

Egwang, Thomas G. Stable support needed for African malaria networks. ScieDevNet.http://www.scidev.net/en/science-and-innovation-policy/southsouth-cooperation/opinions/stable-support-needed-for-african-malaria-networks.html

Ivers, Louise C., Joia S. Mukherjee, Fernet R. Leandre, Jonas Rigodon, Kimberly A. Cullen, and Jennifer Furin. (2010). South-south collaboration in scale-up of HIV care: building human capacity for care. AIDS, 24, S73-S78. DOI: I0.I097/or.aids.0000366085.14064.6f

Jeong, Seonkyoon, Jae Young Choi, and Jaeyun Kim. (20II). The determinants of research collaboration modes: exploring the effects of research and researcher characteristics on co-authorship. Scientometrics, 89 (3), $967-83$.

Knobel, Marcelo. (20I2). Brazil's Student Mobility Initiative. International Higher Education, 66, I5-17.

Knobel, Marcelo, Patricia Simões, T., and Henrique de Brito Cruz, C. (2013). International collaborations between research universities: experiences and best practices. Studies in Higher Education, 38 (3), 405-424.

Knobel, Marcelo. (20I5). Further Reflections on the Brazilian Mobility Program, The World View, Inside Higher Education. https://www. insidehighered.com/blogs/world-view/further-reflections-brazil- 
ian-mobility-program

Organization for Economic Co-operation and Development (OECD). (20II). Global Science Forum: Report on Opportunities, Challenges and Good Practices in International Research Cooperation between Developed and Developing Countries. http://www.oecd.org/dataoecd/40/i6/47737209.pdf.

Osama, Athar. Opportunities and challenges in South-South collaboration. ScieDevNet.

http://www.scidev.net/en/science-and-innovation-policy/south-southcooperation/policy-briefs/opportunities-and-challenges-in-southsouth-collab.html 